de Klerk, E.D., Palmer, J.M., \& Alexander, G. Covid-19 and technology: Higher education's responses to inclusive practices for pre-service teachers with disabilities

\title{
Covid-19 and technology: Higher education's responses to inclusive practices for pre-service teachers with disabilities
}

\author{
Edwin Darrell de Klerk ${ }^{* 1}$, June Monica Palmer² and Greg Alexander ${ }^{2}$ \\ *Corresponding Author: edwin.deklerk@spu.ac.za \\ 1. Sol Plaatje University, Department Education Studies, South Africa \\ 2. Central University of Technology, Department Postgraduate Studies, Free State, South Africa \\ Received : 2021-05-28 \\ Revised : 2021-07-25 \\ Accepted : 2021-08-04
}

dol $10.46303 /$ ressat.2021.7

How to cite this paper: de Klerk, E.D., Palmer, J.M., \& Alexander, G. (2021). Covid-19 and technology: Higher education's responses to inclusive practices for pre-service teachers with disabilities, 6(2), 1-21. https://doi.org/10.46303/ressat.2021.7

This is an Open Access article distributed under the terms of the Creative Commons Attribution 4.0 International license (https://creativecommons.org/licenses/by/4.0/).

\section{Abstract}

Transforming the learning experiences of pre-service teachers with disabilities from stigma and social exclusion to experiencing a sense of belonging, is a desirable imperative for learning mediators in the South African Higher Education (SAHE) context. This paper presents a relational content analysis of the concepts, theories and policies, related to effecting transformation in the meaning schemes of pre-service teachers with disabilities and to provide HEls with inclusive responses to addressing their learning support needs. The theory of perspective transformation, which highlights the process of effecting change in a frame of reference, is applied. The theory expands on three dimensions, including psychological (changes in understanding of the self), convictional (revision of belief systems) and behavioural (changes in lifestyle) with a sound foundation of inclusion aimed at drawing on practices for the prevention of exclusion of the pre-service teacher with disabilities in SAHE spaces. The paper further analyses discourses extracted from Section 47 of the Salamanca Statement, (1994) that build on inclusion artefacts in addressing perspective transformation. The findings in terms of belonging show that affirmations of the discourses, related to an interpersonal connection with others, have the scope to affect pre-service teachers with disabilities' need for a positive regard as a prerequisite to foster the inclusion of individuals within any given relationship. This paper recommends that SAHE institutions embrace an ethos of inclusivity to achieve transformative equity for pre-service teachers with disabilities and offers an inclusive response framework to ensure that they are able to participate, learn and be welcomed as appreciated associates of HEls.

Keywords: Covid-19; Perspective transformation theory; pre-service teachers with disabilities; sense of belonging; transformative learning. 
de Klerk, E.D., Palmer, J.M., \& Alexander, G. Covid-19 and technology: Higher education's responses to inclusive practices for pre-service teachers with disabilities

\section{Introduction}

As the COVID-19 pandemic remains to spread internationally, millions of students in HEls are still affected by sudden shifts away from classroom practices to more innovative and inclusive online teaching and learning strategies in many parts of the world (El Said, 2021). Ongoing education, remote and online learning have become a remedy for this unparalleled worldwide epidemic, notwithstanding the encounters posed to both lecturers and students in HEls. Significantly, changing from customary direct learning to online learning is an entirely new experience for both lecturers and students, to which they had to adjust to speedily (Kalimullina et al., 2021; Pokhrel \& Chhetri, 2021). Nevertheless, the present landscape of inclusive education in South Africa deserves an in-depth monitoring of implementation initiatives. Initiatives are necessary to facilitate change, given the pre-1994 historical, explicitly discriminating infrastructure, and ensuing inequalities regarding access to resources (Alexander \& Mhlongo, 2021).

Sutton (2021) mentions that, generally, students with disabilities in HEls are less likely to believe that they experience a sense of belonging, and that they are deemed equally important, in relation to other students. It seems that students with disabilities often experience the home environment as too distractive, mostly become depressive, due to isolation and a feeling of loneliness, whilst some experience high levels of anxiety, because of uncertainties regarding their future (Sutton, 2021). In a South African study, Kamga (2020) provides an analysis of challenges experienced to apply inclusive education, exploring universal instructions for the future, whilst considering Covid-19 as an opportunity to reconsider how educational preparation for the future can be comprehensive for students with disabilities. In relation to this aspect, it therefore becomes crucial for pre-service teachers with disabilities, aiming to be discernibly effective in an inclusive education atmosphere. Additionally, teachers in post-school settings should familiarize and enlighten themselves with both the direct (school-based) and broader (community) social interfaces, issues and challenges they experience, due to a particular disability (Alexander \& Mhlongo, 2021).

It is significant to note that students with disabilities should be reasonably accommodated within the general education system by having their individual needs recognised and any form of exclusion rejected (United Nations [UN], 2007 as cited in Kamga, 2020). Bearing the significance of inclusion in mind, it is imperative to contemplate that there is a need to ensure that, without imposing undue burden, equality is promoted by provisioning appropriate modifications to the delivery of education for persons with disabilities (UN, 2006, Article 2 as cited in Kamga, 2020). Considering the afore-mentioned stipulations, HEls, therefore, have to 
de Klerk, E.D., Palmer, J.M., \& Alexander, G. Covid-19 and technology: Higher education's responses to inclusive practices for pre-service teachers with disabilities

adopt reasonable accommodation measures in terms of technology, which would entail embracing practical modification methods to ensure the inclusion of students with disabilities.

\section{Research Question}

To promote inclusive practices for pre-service teachers with disabilities, this paper addresses the research question: How can a proposed inclusive response framework for higher education institutions, through an analysis of Salamanca Statements, provide inclusive practices for preservice teachers with disabilities amid the Covid-19 pandemic?

\section{Literature Review}

\section{Learning experiences of pre-services teachers with disabilities}

It is not easy to find an exact description for disability, which precisely and convincingly includes the lived experience of individuals with disabilities. It should be considered that the meaning of disability comes a long way, representative of power undercurrents, preconception and social marginalization of individuals that seem not to belong (Soudien \& Baxen, 2006). According to the Centers for Disease Control and Prevention in the United States of America, a disability may include several categories, such as social relationships, vision, thinking, movement, learning and remembering (Centers for Disease Control and Prevention, 2020). As such, a disability may be described as a situation of the body or mind (impairment) that limits individuals with the condition (disability) to engage in particular activities and to accordingly, interact constructively with their immediate environment (Alexander \& Mhlongo, 2021). Therefore, the way in which people with disabilities (pre-service teachers) participate in several human activities (moving around, learning, interacting or communicating) is reliant on various conditions and aspects conditions, which unavoidably affect their autonomous lifestyles, particular flexibility, learning, and their future occupation prospects as fully competent teachers (Alexander \& Mhlongo, 2021).

Disability may be regarded as impairments and environmental and attitudinal barriers that hinder the effective participation of someone in a society on an equal basis (Department of Social Development [DSD], 2016). Persons with disabilities (also pre-service teachers) experience three foremost categories of interconnected barriers (DSD, 2016). Firstly, social barriers comprise extraordinary costs, absence of disability consciousness, and communication complications; as well as emotional-like anxiety regarding individual well-being. Secondly, psychological barriers include individuals' fear for safety. Thirdly, structural barriers include infrastructure, operations and information. These barriers become a challenge, especially when individuals with disabilities are denied access to full participation in all aspects of life. Also, the barriers (DSD, 2016) can be associated with long-term challenges experienced by pre-service teachers with disabilities (hereafter, PTWD) in HEIs. Some challenges that reverberate with this 
de Klerk, E.D., Palmer, J.M., \& Alexander, G. Covid-19 and technology: Higher education's responses to inclusive practices for pre-service teachers with disabilities

research are the heritage of the South African history that still influences the operations in higher education; the role of institutional diversity; the flexibility of learning, teaching methodologies and issues pertaining to mainstreaming provision (Howell, 2005, as cited in Lyner-Cleophas, 2016). Howell (2015) states that, although disability is part of the current transformation efforts in HEls to address social inequalities, a lack of sufficient policy implementation prolongs the existence of barriers to learning and development for PTWD.

A study conducted in Western Canada (Sokal et al., 2017) reveals that labels of numerous disability sets are applied to assess whether or not PTWD can act as teachers. The latter view (Sokal et al., 2017) embodies a socially constructed interpretation of disability as insufficiency and is an indication of practices and opinions that prolong ableists' worldviews, while guaranteeing sustained opportunities to dominant groups - those pre-service teachers without disabilities. PTWD occasionally display a particular conduct when they engage in teaching practice sessions, raising questions of whether their disability is irreconcilable with meeting the ethics for teachers' skilled practices, even when practices are put into place, which may enhance their learning experiences (Sokal et al., 2017). The findings of a study conducted with $4^{\text {th }}$ year PTWD, ranked their learning experiences in education study courses relatively low (Ezer et al., 2010, as cited in Forkosh-Baruch \& Lipka, 2016). Significantly, the indicated pre-service teachers experienced learning disabilities and gave adapted courses for learning a high ranking, because such courses had a significant impact on their teacher-training. The study proposed that PTWD' learning experiences should include education courses that would impact selfefficacy, whilst adaptive courses are significant for facilitating inclusion principles.

Even if disability was assumed inversely, measured differently or provided for applying diverse techniques, it is obvious that its developing nature emulates the environment within which PTWD experience learning in HEIs. In this regard, the DSD (2016) recommends that there should be, "a mainstreaming of disability to ensure full inclusion of persons with disabilities as equals. The model further encourages that persons with disabilities must actively participate in transformation processes that impact on their lives" (p. 21). Furthermore, those in-service teachers (with and without disabilities) should provide the impetus for redirecting thinking on how all citizens should promote the social values of a democratic and transformed South Africa - this probably via the recognition and acceptance of diversity, more specific to disability issues (Alexander \& Mhlongo, 2021). We argue that the DSD's (2016) view applies to HEls responses to inclusive practices for PTWD.

\section{Inclusive technologies to achieve transformative equity}

Inclusion presupposes the creation of a sense of belonging, tolerance, value and respect for others, while ensuring equal access to learning opportunities and limiting discrimination (DSD, 
de Klerk, E.D., Palmer, J.M., \& Alexander, G. Covid-19 and technology: Higher education's responses to inclusive practices for pre-service teachers with disabilities

2016). Drawing on Nussbaum (2006), the afore-mentioned view implies that HEls should implement special arrangements to ensure that PTWD lead a dignified life, taking into consideration both individual impairment and educational arrangements.

Acknowledging the disabilities of pre-service teachers, HEls should be cognizant about the availability of infrastructure, instruction, need-based approaches and resources for instructional provision, appraisal, and the considerable obvious matter of accommodation and recognition at all levels (Ahmad, 2015b). In this manner it circumvents classifying PTWD, based on their impairment only, therefore HEls should ensure the implementation of inclusive technologies that will build the capacity of both lecturers and pre-service teachers in line with a university's transformation agenda (Mutanga, 2017). Inclusive learning technologies can be defined as those skills, whether hardware or software, that assist students to learn approaches to avoid, work around or recompense for their difficulties (Ahmad, 2015a). Consequently, an effective integration of inclusive technologies may afford PTWD with an ability to access a broad-spectrum education syllabus and offering them numerous means to complete their work with more comfort and freedom (Perelmutter et al., 2017, Kabel et al., 2021). To meet the needs of PTWD, assistive technology (inclusive of equipment, devices, instruments and software) may enhance the learning experiences of PTWD to prevent exclusion from actively participating in their learning and knowledge production, while improving their self-image and sense of belonging (International Organization for Standardization, 2011, as cited in Svensson, 2021, 196; Haßler, et al., 2016). Significantly, technology is viewed as a goal of learning, aiming at developing students' technological literacy and preparing them for working and learning in the $21^{\text {st }}$ century (UNESCO, 2011, as cited in Kopish \& Marques, 2019). Furthermore, the future workplace accommodation (school buildings, infrastructure and facilities) for PTWD should be geared towards making the required resources adjustments: a reasonable and affordable infrastructural, technological and ideological engagement, which embrace diversity where students with disabilities should feel that they are genuinely accommodated within the democratic learning spaces of South Africa (Mhlongo \& Alexander, 2021). Notably, a view by Rapoport (2020) may be deemed applicable here in that he asserts that technology influences engagement, knowledge and skills, whilst the latter may contribute to transformative classroom practices.

When transformation and equity are mentioned in tandem, this paper proposes that the notion of transformative equity may be regarded applicable in its attempt to provide HEls with inclusive responses to addressing the learning support needs of PTWD. Drawing on Shields and Hesbol (2020), we argue that transformative equity requires change knowledge frameworks (perspectives) to ensure equity, in that individuals should become disability responsive. Our view suggests that HEls should evaluate unjust practices and offer the potential, not only for 
de Klerk, E.D., Palmer, J.M., \& Alexander, G. Covid-19 and technology: Higher education's responses to inclusive practices for pre-service teachers with disabilities

better personal attainment, but for a better life lived in community with others (Shields, 2016). In this instance, transformative equity is geared towards how HEls should become aware of their understanding of the plight of a diverse nation and to permit a non-discriminating and inclusive practice by acting upon these understandings (Mezirow, 1990, 14). Significantly, HEls should allow PTWD to make meaning of their existing experiences, so that innovative experiences are embraced and changed. In this way, transformative equity may create possibilities for individuals to start thinking and acting differently (Hoggan et al., 2017).

\section{Disability equity in higher education during covid-19}

Disability may be conceived of as a valuable source of the universal lived experience (Anderson, 2006). In this study, issues pertaining to students with disabilities are relevant to all disadvantaged or marginalised groups, as they are considered as part of the worlds' largest multicultural minority.

The United Nations Convention on the Rights of Persons with Disabilities (UN, 2006), adopted and signed by South Africa in 2007, contains 50 articles and recognizes, "...the inherent dignity and worth and the equal and inalienable rights of all members of the human family as the foundation of freedom, justice and peace in the world..." (UN, 2006, p. 1).

Although this view of the UN (2006) is significant, the COVID-19 pandemic has unearthed and accentuated the plight of students with disabilities. A South African study, investigating lecturers' perceptions on disability inclusion at two universities, revealed that obstructions to inclusion stem from lecturers' dearth of accountability, skills and knowledge in making adaptations to their lectures for disabled students, thereby not addressing their needs and risking their retention (Mutanga \& Walker 2017). Additionally, accessible and flexible online learning may not be available to students with disabilities, although HEls in the main, ostensibly provide such.

McClain-Nhlapo (2020) asserts that issues pertaining to disability equity may be associated with an absence of accessibility, which may result in students with disabilities being excluded from emergency courses offered by HEIS during the Covid-19 pandemic. Thus, although education technologies exist, online equipment frequently lack the rudimentary and essential availability structures to make them practical for students with disabilities. Moreover, even when apparatuses are made with the availability structures, it necessitates skills that may not be freely accessible to several students with disabilities in low- and lower-middle-income nations (McClain-Nhlapo, 2020).

To achieve disability equity, HEls ought to start with collaboration in an attempt to understand why it is imperative to build capacity. Capacity building should be regarded as a way to change mindsets, foster peaceful co-existence, whilst implanting inclusive practices to counterbalance 
de Klerk, E.D., Palmer, J.M., \& Alexander, G. Covid-19 and technology: Higher education's responses to inclusive practices for pre-service teachers with disabilities

student isolation (Ayehsabu, 2020; Snounu, 2019). A broad stakeholder consultative forum (Centers/Units for Disability Access \& Support for Students; Student Representative Council; South African Council for Educators; Teacher Unions; Teaching \& Learning Coordinators; Center for Diversity; Institutional Renewal \& Transformation, etc.), to monitor the implementation of ongoing engagements, are cardinal in promoting diversity and disability equity in HEls' (Alexander \& Mhlongo, 2021).

\section{Theoretical Framework}

In an attempt to provide HEls with tools as to how to respond to inclusive practices for PTWD, this paper employs the theory of perspective transformation, which considers people as actors in the world and how learning changes their thought patterns and world view (Rahman \& Hoque, 2017). When PTWD enter Higher Education Institutions (HEIs), they instantly become aware of particular information that surrounds them, while testing new assumptions and expectations, constantly assimilating and analysing the acquired information to be able to adapt (Mezirow, 2001). The imperative for HEls is to create inclusive practices where PTWD are guided in terms of engaging in transformative and adaptive learning toward more inclusive, open, and reflective practices (Mezirow, 2003).

A transformative approach to newly gained perspectives provides opportunities for challenging expectations, interrogating ways of knowing, and analytically appraising different viewpoints, in order to bring about wider, more comprehensive perspectives (Herbers \& Nelson, 2009). The theory expands on three dimensions, including psychological (changes in understanding of the self), convictional (revision of belief systems) and behavioural (changes in lifestyle), with a sound foundation of inclusion aimed at drawing on practices for the prevention of exclusion of the pre-service teacher with disabilities in SAHE spaces. Perspective transformation is useful in this paper, in that it may guide HEls on how to employ open dialogue in which all participants are afforded opportunities to express their concerns and perspectives (Gould, 2002). Significantly, in such dialogues, HEls should focus on pre-service teachers' abilities to transform their understanding of the self, review their own belief structures and bring about changes in their lives (Mezirow, 2003).

\section{Method}

Qualitative content analysis, "is systematic and analytic but less rigid than quantitative content analysis, and the researcher constantly revises the themes or categories by moving back and forth between conceptualization, data collection, analysis, and interpretation" (Bell et al., 2019, 511). Two categories of content analysis exist, including relational analysis and conceptual analysis. (Wilson, 2011). Conceptual analysis is fundamentally applied when content is coded for particular words, ideas, or themes, and the researcher would make extrapolations founded 
de Klerk, E.D., Palmer, J.M., \& Alexander, G. Covid-19 and technology: Higher education's responses to inclusive practices for pre-service teachers with disabilities

on the patterns that transpire. Relational analysis is complementary to conceptual analysis in that it delves into the interactions between concepts that become apparent from the examined texts. This paper employs a relational content analysis to analyse discourses in the Salamanca Statement (UNESCO, 1994). It implies that relational analysis tolerates more elucidation than conceptual analysis, because it goes beyond the regularity of specific ideas and allows for interpretations to be made about inclusive significance. When researchers apply relational analysis to education policy content, they (researchers) are positioned central to the process of meaning making of texts (Bell et al., 2019).

To conduct a relation analysis of statements, we took the following steps. Firstly, a sample of statements from the Salamanca Statement (UNESCO, 1994) were selected - the selection was based on statements that strongly speak to inclusive practices for pre-service teachers with disabilities. Secondly, the statements (UNESCO, 1994) were aligned with the dimensions of perspective transformation as described in the theoretical framework. Thirdly, three inclusive responses for HEls have been identified which were analysed in relation to the statements (UNESCO, 1994) and dimensions of perspective transformation. With reference to relational analysis, the identified responses are relevant to the analysis of texts in the Salamanca Statement (UNESCO, 1994). These inclusive responses are: transformative inclusivity for preservice teachers with disabilities; positive regard for pre-service teachers with disabilities and assisting pre-service teachers with disabilities to enact a sense of belonging. In an attempt to show understanding, the researchers (henceforth referred to as Chris, Amanda and Alan) added anecdotes, which entail brief explanations about their own experiences with inclusive practices at HEls, in terms of pre-service teachers with disabilities.

Significantly, the Salamanca Statement (UNESCO, 1994), was developed from the collective dream of 94 nations that supported schooling as a right of all children, with the conviction that schools have the mandate to accommodate diverse learners, irrespective of their intellectual, physical, emotional, linguistic and social afflictions (UNESCO, 1994). The Salamanca Statement is clear that a transformation in perspectives is necessitated to ensure that people with disabilities are provided appropriate opportunities to participate in educational programmes, outlining the advisory role that universities should assume in actively involving people with disabilities in research and training roles, while considering their perspectives respectfully and without reservation (UNESCO, 1994). Arguably, when HEls consider perspectives in the Salamanca Statement (UNESCO, 1994), PTWD will be afforded opportunities to design their personal lifestyles and ambitions with dignity. 
de Klerk, E.D., Palmer, J.M., \& Alexander, G. Covid-19 and technology: Higher education's responses to inclusive practices for pre-service teachers with disabilities

\section{Results and Discussion}

The discussion correlates with the research question: How can a proposed inclusive response framework for higher education institutions, through an analysis of Salamanca Statements, provide inclusive practices for pre-service teachers with disabilities amid the Covid-19 pandemic? An inclusive response may be viewed as an act to ensure that all students are able to participate, learn and are welcomed as appreciated associates of HEls (Morgado et al., 2016). Notably, an inclusive response transpires when circumstances are created to encourage inclusive practices to meet the needs of all students (Fernández, 2014, as cited in Colón et al., 2018). This paper proposes the following: "inclusive response framework" (Figure 1).

To extrapolate the relational aspect of concepts contained in Section 47 of the Salamanca Statement (UNESCO, 1994), concepts including "involve people", "to ensure" and "taken fully into account", were explored. We aligned the constructed meanings with additional stipulations in the Salamanca Statement to show its relation to aspects of perspective transformation, in order to propose inclusive responses for HEls to address PTWDs learning support needs. The following inclusive responses will consequently be discussed: transformative inclusivity for pre-service teachers with disabilities; positive regard for preservice teachers with disabilities and assisting pre-service teachers with disabilities to enact a sense of belonging. 
de Klerk, E.D., Palmer, J.M., \& Alexander, G. Covid-19 and technology: Higher education's responses to inclusive practices for pre-service teachers with disabilities

Figure 1: Inclusive response framework

\section{Section 47 (Salamanca Statement, UNESCO, 1994)}

"It is also important to actively involve people with disabilities in research and training roles in order to ensure that their perspectives are taken fully into account" (UNESCO, 1994, 29).

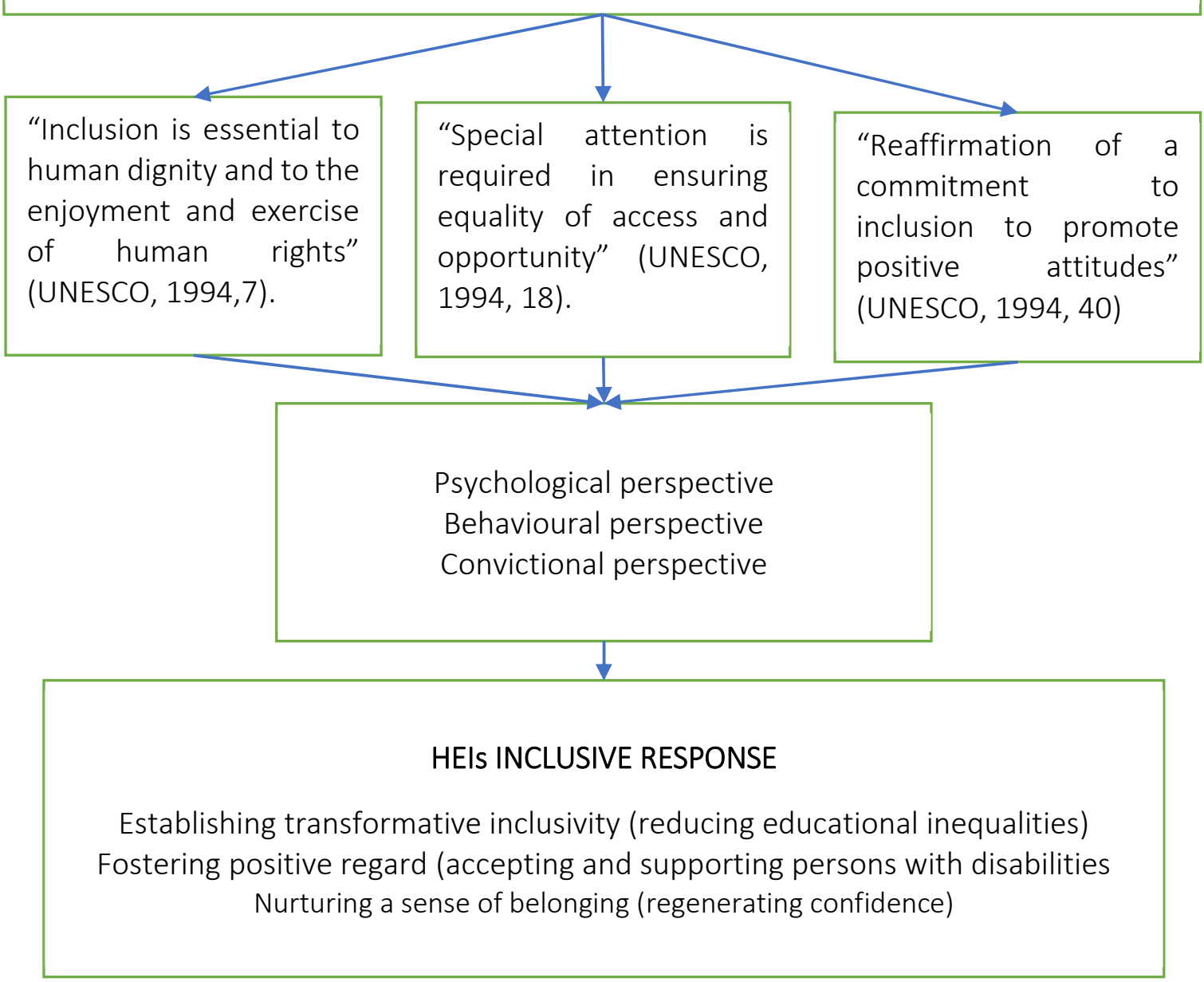


de Klerk, E.D., Palmer, J.M., \& Alexander, G. Covid-19 and technology: Higher education's responses to inclusive practices for pre-service teachers with disabilities

\section{Transformative inclusivity for pre-service teachers with disabilities}

The use of "involve people" (UNESCO, 1994), signifies a transformative inclusivity tool, aligned with the notion of human rights and an autonomous way of considering morals and developing opinions, which celebrate human diversity (Maguvhe, 2015). For HEls to "involve people", a welcoming learning environment should be created through inclusive participation, to enable PTWD to optimise genuine opportunities for self-representation skills, among others. Observing the basic rights of PTWD, while preserving their human dignity, is a cornerstone of any inclusive practice and a necessary imperative for HEls.

Additionally, HEIs' response to PTWD should be geared towards fostering individuals' sense of confidence and dignity, as well as catering to their emotional and physical vulnerabilities. Providing equitable teaching and learning experiences, while confidently changing and enhancing their self-esteem is key. In this regard, Chris told the following story:

I believe that it is imperative to have faith in my students. In showing that I have faith in them, they realise that I see them as autonomous individuals, deserving of respect. I concede that the value I have for them, paved the way for a deeper trust, which I find is so vital in any given relationship where deep learning is an objective. By trusting them fully, and believing in their abilities, I realised that they exude a profound sense of self-worth and confidence. This simple act helped them to value themselves, to think differently about who they are and to be aware and use opportunities that are afforded to them.

Considering Chris' story from a psychological perspective and drawing on Mezirow (1991), HEls should assist students to grow in awareness and stature, while being cognisant of their experiences and reflections (how they are thinking, feeling, judging and acting).

For this purpose, HEls may be positioned to assist PTWD to restructure their frames of reference, which determine how they make meaning of their current experiences. It is, therefore, necessary that a transformative inclusive climate, with flexible and relevant educational programming, be created. Transformative inclusivity would require that HEls foster inclusive, multidimensional learning, which would include actions to create equitable opportunities for PTWD. A democratic approach in responding to critical human rights issues by relevant stakeholders within the South African HEIs' landscapes and those pre-service teachers receiving tertiary training, should be construed as a collaborative effort in empowering PTWD through the creation of a dialogical atmosphere of equality. 
de Klerk, E.D., Palmer, J.M., \& Alexander, G. Covid-19 and technology: Higher education's responses to inclusive practices for pre-service teachers with disabilities

\section{Positive regard for pre-service teachers with disabilities}

The use of "to ensure" (UNESCO, 1994), is not only about adjusting to accommodate diversity, but to create equal access to teaching and learning opportunities. This implies that HEls should deliberately implement actions that safeguard inclusivity and use difference as a stimulus for fostering learning, participation, and achievement. This kind of inclusion aligns with a stipulation in the Salamanca Statement, which highlights that, "Special attention is required in ensuring equality of access and opportunity" (UNESCO, 1994, 18). The significance of an inclusive response, encapsulating equality of access and opportunity, suggests equal access to resources, mining the talents, intelligences, and abilities of individuals with disabilities.

Consequently, HEls should ensure that access and opportunities are emphasised through training stakeholders around disability awareness, recognising that diversity brings richness, new ideas, growth, and dynamism (Fredette et al., 2015). In her reflection, Amanda had the following to say:

I am of opinion that a combination of high expectations and effective instruction indicate a proven way to express hope to students. By instilling hope, I realised that I was able to strengthen PTWD to believe in their own capacities, by adapting my teaching pedagogies so that every student would feel included. I frequently assessed my own pedagogies by requesting PTWD to demonstrate what they have learned and assisted them where necessary. In so doing, I constantly explored their practices to better articulate, understand and further identify and improve upon their educational needs. This allowed them to contribute towards change in their own behaviour, as well as in their perspective about their university.

Interpreting Amanda's story from a behavioural perspective, HEls may use mindfulness as a supplementary knowledge practice to assist PTWD to develop insights into their customary modes of thinking, which then allows them to alter negative patterns of thinking and subsequently responding differently in these situations. Importantly, mindfulness teaching may help PTWD to "step-out" of disapproving behaviour patterns, paying specific consideration to their existing experience, so that they (PTWD) unconditionally feel good about themselves.

This implies that HEls should assist PTWD to reach their highest potential, also known as selfactualisation. We contend that developing self-actualization can help PTWD to unravel difficulties innovatively, embrace transformation, and promote profound and significant relationships. Thus, by supporting PTWD, a person-centered approach is proposed, one of understanding acceptance and change so that they experience feelings of belonging. 
de Klerk, E.D., Palmer, J.M., \& Alexander, G. Covid-19 and technology: Higher education's responses to inclusive practices for pre-service teachers with disabilities

\section{Assisting pre-service teachers with disabilities to enact a sense of belonging}

The use of "taken fully into account" (UNESCO, 1994), has reference to gaining acceptance, attention, and support from others. Evidently, HEls' response should be to model different social relations and possibilities, while recognising that students with disabilities are valued and that their achievements are celebrated. In terms of inclusion, recognising the abilities of PTWD can be associated with the Salamanca Statement, because it may refer to a, "Reaffirmation of a commitment to inclusion to promote positive attitudes" (UNESCO, 1994, 40). HEIs should deliberately facilitate actions aimed at modifying fundamental feelings and beliefs, as well as the co-existence of encouraging and undesirable characters. Considering the afore-mentioned, Alan mentioned:

I always encourage my PTWD to invite me into their spaces, their social digital worlds, sharing on a professional level. In so doing, I try to bridge the gap between PTWD and other students. I realised that regular communication was the key in reimaging my classes. I afford my students the space to share their emotions and connect with each other. In this way, I assist them to create communities of practice and to establish solid academic relationships - all recipes for helping them to experience a sense of belonging.

We found in Alan's story, from a relational perspective, that lecturers at some HEls already assist PTWD to revise their belief systems, so that they actively transform the ways in which they (PTWD) would make decisions. In this regard, we propose that HEls should establish emotional and social learning in classroom situations, while enabling social spaces for all students to work together and support initiatives that would nurture an exchange of ideas. In so doing, HEls would be in a position to strengthen PTWD' sense of belonging.

A sense of belonging can assist in improving students' academic achievement, because it is a human need and a fundamental motive, sufficient to drive human behaviour. HEls should, therefore, take ownership of PTWD' development so that they may be positioned to reinventing themselves to belong. In so doing, PTWD may become transformative agents who strive to be successful within an academic space where HEls provide inclusive, equitable and socially responsible practices.

The analysis of Section 47 of the Salamanca Statement (UNESCO, 1994), provides useful HEIs' responses to inclusive practices for PTWD. Arguably, if HEls would acknowledge the significance of responding appropriately to the needs of PTWD, they (HEIs) may play a crucial role in enhancing transformative inclusivity, a positive regard and a sense of belonging where disability 
de Klerk, E.D., Palmer, J.M., \& Alexander, G. Covid-19 and technology: Higher education's responses to inclusive practices for pre-service teachers with disabilities

inclusion would form a significant part of a re-imagined society. This would then align with the notion that, in order to create a caring and inclusive society where all assume equal responsibility to build it, the potential and rights of all its citizens will be protected.

An implementation of the proposed HEls' responses may thus contribute to nation building where multiplicity, socio-economic wellness and citizenship could be promoted.

\section{Concluding Reflections}

This theoretical paper attempted to answer the question: How can a proposed inclusive response framework for higher education institutions, through an analysis of Salamanca Statements, provide inclusive practices for pre-service teachers with disabilities amid the Covid19 pandemic? The analysis of the Salamanca Statement (UNESCO, 1994) and the proposed inclusive response framework, revealed three responses which, when implemented, may assist HEls to foster a more conducive education environment for PTWD. Firstly, when HEls would implement transformative inclusivity, it may assist PTWD to appreciate a multidimensional learning environment where equal opportunities are afforded to all students and it would include actions to create equitable opportunities for all. Secondly, HEls should foster a positive regard to enable PTWD to experience a stronger sense of self-worth, thus helping them to become more confident and motivated. Thirdly, when PTWD are assisted to enact a stronger sense of belonging, they (PTWD) may regard themselves as equally important, in relation to other students.

This paper supports other findings in the academic literature on the role of HEls to respond to inclusive practices for PTWD. HEls should create conducive environments for diverse students to thrive through exhibiting consideration, kindness and exercising an obligation to inclusivity.

The findings further reflect that HEls should employ person-centred approaches in assisting PTWD in acquiring appropriate levels of self-actualisation, which might be realised through the promotion of the supportive acknowledgement and discussion, pertaining to disability. Gaining insight into the issue of self-disclosure involves explaining sensitive information so that fellow students without disabilities and lecturing staff, value notions around transparency, equity, respect, and acceptance of diversity - these values should be espoused during class engagements and social interactions. Furthermore, promoting effective classroom communities where all PTWDs may fulfil their optimal potential, becomes all-important. Inclusive teaching and learning activities could possibly be structured to empower a sense of belonging, care, trust, and constructive conversations about disability, while ensuring the 
de Klerk, E.D., Palmer, J.M., \& Alexander, G. Covid-19 and technology: Higher education's responses to inclusive practices for pre-service teachers with disabilities

availability of accommodations and or modifications, infrastructure, facilities and learning support materials.

This paper suggests that an empirical study be conducted, which would include the voices of PTWD regarding their experiences of inclusivity in HEls. Understanding what challenges PTWD may experience regarding inclusivity, may assist HEls in planning for future accessibility needs during times of extreme stress and beyond. 
de Klerk, E.D., Palmer, J.M., \& Alexander, G. Covid-19 and technology: Higher education's responses to inclusive practices for pre-service teachers with disabilities

\section{References}

Ahmad, F.K. (2015a). Use of Assistive Technology in Inclusive Education: Making Room for Diverse Learning Needs. Transcience: A Journal of Global Studies, 6(2), 62-77.

Ahmad, F.K. (2015b), "Exploring the Invisible: Issues in Identification and Assessment of Students with Learning Disabilities in India." Transcience: A Journal of Global Studies, 6(1), 91-107.

Ainscow, M. (2020). Inclusion and equity in education: Making sense of global challenges. Prospects, 49, 123-134.

Aksu, T., \& Cantürk, G. (2015). Equality of Educational Opportunity: The Role of Using Technology in Education. International Journal of Academic Research in Progressive Education and Development, 4(4), 79-93.

Alexander, G. \& Mhlongo, D. (2021). Creating a Democratic Culture in Managing Classroom Contexts of Disability- PART 1 [Online First], IntechOpen, DOI: 10.5772/intechopen.96433. Available from: https://www.intechopen.com/onlinefirst/creating-a-democratic-culture-in-managing-classroom-contexts-of-disability-part1

Anderson, R.C. (2006). Teaching (with) Disability: Pedagogies of Lived Experience. The Review of Education, Pedagogy, and Cultural Studies, 28(3-4), 367-379.

Ayehsabu, A.P. (2020). Promoting inclusiveness through an inclusive leadership framework in culturally diverse South African schools. PhD-dissertation. Potchefstroom: North-West University.

Bell, E., Bryman, A., \& Harley, B. (2019). Business Research Methods (5 $5^{\text {th }}$ ed.). Oxford, UK: Oxford University Press.

Cefai, C., Bartolo, P.A., Cavioni, V., \& Downes, P. (2018). Strengthening social and emotional education as a core curricular area across the EU: A review of the international evidence (NSET I/ Report). Publications of the European Union. Available at: https://doi.org/10.2766/664439 (Accessed 12 May 2021).

Centers for Disease Control and Prevention. (2020). Health Overview. Impairments, Activity Limitations, and Participation Restrictions. Available at: https://www.cdc.gov/ncbddd/disabilityandhealth/disability.html (Accessed 17 May 2021).

Collins, A., Azmat, F., \& Rentschler. (2018). Bringing everyone on the same journey': revisiting inclusion in higher education. Studies in Higher Education, 44(8), 1475-1487.

Colón, A.M.O., Montoro, M.A., \& Ruiz, M.J.C. (2018). Toward inclusive higher education in a global context. Sustainability, 10, 1-13.

De Angelis, R. (2018). Entwining a conceptual framework: Transformative, Buddhist and indigenous-community learning. Journal of Transformative Education, 16, 176196.

De Klerk, E.D. (2020). Reinforcing Pre-Service Teachers' Sense of Belonging Through 
de Klerk, E.D., Palmer, J.M., \& Alexander, G. Covid-19 and technology: Higher education's responses to inclusive practices for pre-service teachers with disabilities

Transformative Leadership Perspectives. In Srisawasdi, N. et al. (Eds.), Proceedings of the 13th International Conference on Educational Research (pp. 181-189. Thailand:

Faculty of Education, Khon Kaen University.

De Klerk, E.D., \& Palmer, J.M. (2021). Resetting education priorities during Covid-

19: towards equitable learning opportunities through inclusion and equity.

Perspectives in Education, 39(1), 12-28.

Department of Social Development (DSD). (2016). White paper on the rights of persons with disabilities. Pretoria: Government Printer.

Florian, L. (2019). On the Necessary Co-Existence of Special and Inclusive Education. International Journal of Inclusive Education, 23(7-8), 691-704.

El Said, G.R. (2021). How Did the COVID-19 Pandemic Affect Higher Education Learning Experience? An Empirical Investigation of Learners' Academic Performance at a University in a Developing Country. Hindawi Advances in Human-Computer Interaction, 2021, Article ID 6649524. Available at: https://doi.org/10.1155/2021/6649524 (Accessed 17 May 2021).

Farnell, T. (2020). Community engagement in higher education: Trends, practices and policies (NSET Report). Publications Office of the European Union. Available at: https://doi.org/10.5897/ijsa11.084 (Accessed 12 May 2021).

Florian, L. (2019). On the necessary co-existence of special needs and inclusive education. International Journal of Inclusive Education, 23(7-8), 691-704.

Forkosh-Baruch, A., \& Lipka, O. (2016). Pre-Service Teachers with Learning Disabilities: Perceptions of Professional Training. Psychology Research, 6(8), 455-465.

Fredette, C., Bradshaw, P., \& Krause, H. (2015). From Diversity to Inclusion: A Multimethod Study of Diverse Governing Groups. Nonprofit and Voluntary Sector Quarterly, 45(1), 28S-51S.

Gould, J. (2002). Thinking with the heart: provoking emotion as a tool for learning. Journal of Excellence in College Teaching, 13(1), 5-27.

Haßler, B., Major, L., \& Hennessy, S. (2016). Tablet use in schools: a critical review of the evidence for learning outcomes. Journal of Computer Assisted Learning, 32, 139-156.

Herbers, M.S., \& Nelson, B.M. (2009) Using the disorienting dilemma to promote transformative learning. Journal of Excellence in College Teaching, 20(1), 5-34.

Hirsch, J.L., \& Clark, M.S. (2019). Multiple paths to belonging that we should study together. Perspectives on Psychological Science, 14(2) 238-255.

Hoggan, C., Mälkki, K., \& Finnegan, F. (2017). Developing the Theory of Perspective Transformation: Continuity, Intersubjectivity, and Emancipatory Praxis. Adult Education Quarterly, 67(1), 48-64.

Howell, C. (2015). Guidelines for the creation of equitable opportunities for people with disabilities in South African Higher Education. Stellenbosch: Cape Higher Education Consortium (CHEC). 
de Klerk, E.D., Palmer, J.M., \& Alexander, G. Covid-19 and technology: Higher education's responses to inclusive practices for pre-service teachers with disabilities

Hussein, J.W., Bedasa, N.A., \& Mengistu, B.T. (2019). Integrating reflective problemsolving and mindfulness to promote organizational adaptation toward conflict sensitivity. Journal of Transformative Education, 17, 24-50.

Kabel, M., Hwang, J., \& Hwang, J. (2021). Lessons Learned from a Rural Classroom Study: Transitioning from Concrete to Virtual Manipulatives to Teach Math Fact Fluency to Students with Learning Disabilities. Journal of Curriculum Studies Research, 3(1), 42-68. https://doi.org/10.46303/jcsr.2021.7

Kalimullina, O., Tarman, B. \& Stepanova, I. (2021). Education in the Context of Digitalization and Culture: Evolution of the Teacher's Role, Pre-pandemic Overview. Journal of Ethnic and Cultural Studies, 8(1), 226-238. DOI: http://dx.doi.org/10.29333/ejecs/629

Kamga, S.D. (2020). COVID-19 and the inclusion of learners with disabilities in basic education in South Africa: A critical analysis. African Human Rights Law Journal, 20, 558-583.

Kopish, M., \& Marques, W. (2019). Leveraging Technology to Promote Global Citizenship in Teacher Education in the United States and Brazil. Research in Social Sciences and Technology, 5(1), 45-69.

Lazar, J. (2021). Managing digital accessibility at universities during the COVID-19 pandemic. Universal Access in the Information Society, 2020,1-17. Available at: https://link.springer.com/content/pdf/10.1007/s10209-021-00792-5.pdf (Accessed 21 May 2021).

Leifler, E. (2020). Teachers' capacity to create inclusive learning environments. International Journal for Lesson \& Learning Studies, 9(3), 221-224.

Lyner-Cleophas, M.M. (2016). Staff and disabled students' experiences of disability support, inclusion and exclusion at Stellenbosch University. PhD-dissertation. Stellenbosch: Stellenbosch University.

Maguvhe, M. (2015). Inclusive education: A transformation and human rights agenda under spotlight in South Africa. African Journal of Disability, 4(1), a183. Available at: https://doi.org/10.4102/ajod.v4i1.183 (Accessed 11 May 2021).

Maguvhe, O. (2015). Equality, equity and empowerment: The place for advocacy. In O. Maguvhe \& M.D. Magano (eds.), Disability in context: A socio-educational perspective in South Africa (pp. 128-143), Hampshire: CENGAGE Learning EMEA.

Marcinkowski, T., \& Reid, A. (2019). Reviews of research on the attitude-behavior relationship and their implications for future environmental education research. Environmental Education Research, 25(4), 459-471.

Marcus, D. (2014). Human dignity: Concepts, discussions, philosophical perspectives. In D. Marcus, B. Jens \& M Dietmar (Eds.), The Cambridge Handbook of Human Dignity (pp. 23-52). Cambridge, UK: Cambridge University Press.

McClain-Nhlapo, C. (2020). An inclusive response to COVID-19: Education for 
de Klerk, E.D., Palmer, J.M., \& Alexander, G. Covid-19 and technology: Higher education's responses to inclusive practices for pre-service teachers with disabilities

children with disabilities. Available at:

https://www.globalpartnership.org/blog/inclusive-response-covid-19-educationchildren-disabilities (Accessed 17 May 2021).

McHenry, L.K. (2018). A Qualitative Exploration of Unconditional Positive Regard and its Opposite Constructs in Coach-Athlete Relationships. Master's Thesis. Tennessee: University of Tennessee.

McIntosh, N.A., \& Nenonene, R.L. (2020). In This Spirit: Helping Preservice Teachers Thrive During the In This Spirit: Helping Preservice Teachers Thrive During the Pandemic Through Adaptation and Change Pandemic Through Adaptation and Change. Journal of Catholic Education, 23(1), 162-174.

Mezirow, J. (1991). Transformative dimensions of adult learning. San Francisco, CA: Jossey-Bass.

Mezirow, J. (1990). How critical reflection triggers transformative learning. In J. Mezirow (Ed.), Fostering critical reflection in adulthood (pp. 1-20). San Francisco, CA: Jossey-Bass.

Mezirow, J. (2001). Learning to think like an adult. Core concepts of transformation theory. In J. Mezirow \& Associates (Eds). Learning as transformation critical perspective on a theory in progress (pp. 3-34). San Francisco, CA Jossey-Bass.

Mezirow, J. (2003). Transformative learning as discourse. Journal of Transformative Education, 2003(1), 58-63.

Mhlongo, D. \& Alexander, G. (2021). Sustaining a Democratic Culture through Collaborative Engagements for Citizens with Disabilities: Part 2 [Online First], IntechOpen, DOI: 10.5772/intechopen.96782. Available from: https://www.intechopen.com/online-first/sustaining-a-democratic-culture-throughcollaborative-engagements-for-citizens-with-disabilities-part-2.

Morgado, B., Cortez-Vega, M.D., López-Gavira, R., Alvarez, E., \& Moriña, A. (2016). Inclusive education in higher education. Journal of Research in Special Educational Needs, 16(s1), 639-642.

Morris, T.H. (2020). Transformative learning through mindfulness: Exploring the mechanism of change. Australian Journal of Adult Learning, 60(1), 44-65.

Murphy, M.C., Gopalan, M., Carter, E.R., Emerson, K.T.U., Bottoms, B.L., \& Walton, G.M. (2020). A customized belonging intervention improves retention of socially disadvantaged students at a broad-access university. Sciences Advances, 6(29), 1-7.

Mutanga, O. (2017). Students with disabilities' experience in South African higher education - a synthesis of literature. South African Journal of Higher Education, 31(1), 135-154.

Mutanga, O., \& Walker, M. (2017). Exploration of the Academic Lives of Students with Disabilities at South African Universities: Lecturers' Perspectives. African Journal of Disability 6(0), a316. DOI: https://doi.org/10.4102/ajod.v6i0.316

Nussbaum, M. (2006). Frontiers of justice: Disability, nationality, species membership. 
de Klerk, E.D., Palmer, J.M., \& Alexander, G. Covid-19 and technology: Higher education's responses to inclusive practices for pre-service teachers with disabilities

Cambridge, Mass: Belknap Press.

Perelmutter, B., McGregor, K.K., \& Gordon, K.R. (2017). Assistive technology interventions for adolescents and adults with learning disabilities: an evidence-based systematic review and meta-analysis. Computers \& Education, 114, 139-163.

Pokhrel, S., \& Chhetri, R. (2021). A Literature Review on Impact of COVID-19 Pandemic on Teaching and Learning. Higher Education for the Future, 8(1), 133-141.

Rahman, M.M., \& Hoque, A.K.M. (2017). Transformative Learning: A Concept and Powerful Vision for Adult Education. Anwer Khan Modern Medical College Journal, 8(2), 128-131.

Rapoport A. (2020). Editorial: Technologization of Global Citizenship Education as Response to challenges of Globalization. Research in Social Sciences and Technology, 5(1), i-vii.

Rogers, C. (1957). The Necessary and Sufficient Conditions of Therapeutic Personality Change. Journal of Consulting Psychology, 21(2), 95-103.

Shields, C.M. (2016). Transformative leadership in education: Equitable and socially just change in an uncertain and complex world (2nd ed.). New York, NY: Routledge.

Shields, C.M. (2018). Transformative leadership in education: Equitable and socially just change in an uncertain and complex world. New York, NY: Routledge.

Shields, C.M., \& Hesbol, K.A. (2020). Transformative Leadership Approaches to Inclusion, Equity, and Social Justice. Journal of School Leadership, 30(1), 3-22.

Slee, R. (2019). Belonging in an age of exclusion. International Journal of Inclusive Education, 23(9), 909-922.

Snounu, Y. (2019). Disability and Higher Education in Palestine. Journal of Culture and Values in Education, 2(3), 61-78. https://doi.org/10.46303/jcve.03.02.4

Sokal, L., Woloshyn, D., \& Wilson, A. (2017). Pre-service Teachers with Disabilities: Challenges and Opportunities for Directors of Student Teaching in Western Canada. The Canadian Journal for the Scholarship of Teaching and Learning, 8(3), Article 7. Available at: http://ir.lib.uwo.ca/cjsotl_rcacea/vol8/iss3/7 (Accessed 07 May 2021).

Soudien, C., and Baxen, J. (2006). Disability and schooling in South Africa. In B. Watermeyer, L. Swartz, T. Lorenzo, M. Schneider \& M. Priestley (eds.), Disability and social change (pp. 149-163). Cape Town: HSRC Press.

Sutton, H. (2021). Covid-19 disproportionately impacts students with disabilities across all sectors. Disability Compliance for Higher Education, 26(6), 9. Available at: https://onlinelibrary.wiley.com/doi/epdf/10.1002/dhe.30973 (Accessed 17 May 2021).

Svensson, I., Nordström, T., Lindeblad, E., Gustafson, S., Björn, M., Sand, C., Almgren/Bäck, G., \& Nilsson, S. (2021). Effects of assistive technology for students with reading and writing disabilities. Disability and Rehabilitation: Assistive Technology, 16(2), 196-208.

Ulriksen, L., Madsen, L.M., \& Holmegaard, H.T. (2017). The first-year experience of 
de Klerk, E.D., Palmer, J.M., \& Alexander, G. Covid-19 and technology: Higher education's responses to inclusive practices for pre-service teachers with disabilities

non-traditional students in Danish science and engineering university programmes.

European Educational Research Journal, 16(1), 45-61.

UNESCO. (1994). The Salamanca statement and framework for action on special needs education. Spain: UNESCO.

United Nations (UN). (2006). Convention on the Rights of Persons with Disabilities (UNCRPD). Available at:

https://www.un.org/development/desa/disabilities/convention-on-the-rights-ofpersons-with-disabilities.html (Accessed 21 May 2021).

United Nations (UN). 2015. Transforming our world: The 2030 agenda for sustainable development. Available at:

http://www.un.org/ga/search/view_doc.asp?symbol=A/RES/70/1\&Lang=E (Accessed 11 May 2021).

Wilson, V. (2011). Research Methods: Content Analysis. Evidence Based Library and Information Practice, 6(4), 177-179. 